There are many methodological problems inherent in attempting to demonstrate that an educational course is meeting its objectives. Our present study reflects some of these. Not least of the problems is that, in any day release course spread over several months, the trainees are inevitably learning by their everyday clinical experience as well as the formal teaching they receive on the course. Nevertheless, attempts to evaluate the applicability and value of training courses is important if we are to avoid costly and inappropriate teaching.

The current study demonstrates that a structured interview skills course was perceived as useful and of clinical and educational value by trainee psychiatrists. One further measure of its success or otherwise is in the proportion of trainees who pass the Part I at their first attempt. Seven of the trainees who attended the interview skills workshops sat the Part I examination in October 1987. These trainees had all attended three or more workshops. Six $(85.7 \%)$ passed at this first attempt. The one trainee who failed the examination passed the clinical section and failed on the MCQ paper. Although it is impossible to attribute this high success rate to any one factor, it is at least reassuring that our trainees were so successful.

The ultimate value of all medical education must be in producing clinically skilled, sensitive and knowledgeable doctors. However, the assessment of how much clinical courses may specifically contribute to this objective is beyond the scope of this present study. Considerable work remains to be done in addressing the issue of designing objective measures to evaluate clinical skills.

\section{ACKNOWLEDGEMENTS}

We are extremely grateful to Drs J. Gayford, P. Hill and B. Matthews who spent many hours rating the videotapes.

\section{REFERENCES}

'Royal College of Psychiatrists (1985) Working Party for Review of the MRCPsych. Report to the Court of Electors.

2Maguire, P., Roe, P., Goldberg, D., Hyde, S., Jones, D. \& O'DowD, T. (1978) The value of feedback in teaching interview skills to medical students. Psychological Medicine, 8, 695-704.

${ }^{3}$ Magutre, P., Fatrburn, S. \& Fletcher, C. (1986) Consultation skills of young doctors: (1) Benefits of feedback training in interviewing as students persist. British Medical Journal, 292. 1573-1576.

${ }^{4}$ Byrne, P. S. \& LoNG, B. L. (1976) Doctors Talking with Patients. London: HMSO.

sLieberman, S., Hafner, R. J. \& Crisp, A. H. (1978) Teaching psychotherapy in mental hospitals, British Journal of Psychiatry, 132, 398-402.

${ }^{6}$ Drummond, L. M. \& Bhat, A. V. (1987) A regional survey of the training of junior psychiatrists in behavioural psychotherapy, Bullet in of the Royal College of Psychiatrists, 11, 126-128.

'HAFNer, R. J., Lieberman, S. \& CRISP, A. H. (1977) A survey of consultant psychiatrists' attitude to their work with particular reference ot psychotherapy, British Journal of Psychiatry, 131, 415-419.

${ }^{8}$ GoOdYeAR, P. (1987) Conference for psychiatric tutors in teaching interview skills. Bulletin of the Royal College of Psychiatrists. $11,344$.

A full list of references is available from Dr Drummond on request.

\title{
Organising the MRCPsych Part I Clinical Examination
}

G. H. McDonald, Senior Registrar, Purdysburn Hospital, Belfast; O. Daly, Senior House Officer, Royal Victoria Hospital, Belfast and C. CAssidy, Registrar, Purdysburn Hospital, Saintfield Road, Belfast

In Autumn 1987 the new Part I Membership examination was held for the first time. The format was changed in response to the Royal College of Psychiatrists Working Party, who recommended that it should become an examination in basic clinical psychiatry. ${ }^{1}$ It was felt to be important that clinical skills were assessed early in training.

To a certain extent, those of us involved in organising the clinical part of the new examination were entering virgin territory as the requirements are different to those of the new membership clinical examination. We believe it would be helpful to future organisers to discuss our experiences and point out some of the possible pitfalls in the administration of the examination.

Useful information can be gathered from the experience of organisers in other medical specialities where clinical examinations are used. ${ }^{2.3}$ Advice may also be sought from those who have co-ordinated the MRCPsych II examination. It is interesting that Armstrong \& Loosemore ${ }^{4}$ report similar experiences to our own.
Each of the examination centres throughout the British Isles accommodates up to $\mathbf{3 2}$ candidates over two days. They are examined by two pairs of examiners from outside the region. On one of the examination days a College observer attends, with the remit of examining the suitability of the examination centre, the performance of the examiners, and the suitability of the patients selected. Although not directly examining the candidates, it can be presumed that his incursion will increase their anxiety level. At local level the examination is co-ordinated by a senior organiser appointed by the College. The senior organiser (a local consultant) in turn selects an organiser (senior registrar) and two stewards (registrar/SHO).

\section{Before the examination}

Planning the examination involves considerable disruptions to the host hospital. Permission to hold the examination must be sought from Unit Management who will then 
help to co-ordinate the various ancillary services required e.g. catering, signposting, office equipment and switchboard facilities. The catering department is asked to provide morning coffee, examiners' lunches and afternoon tea. Facilities should also be available for candidates' lunches. Signposting must be clear and comprehensive. In addition to secretarial support, access to a photocopier is essential. Switchboard staff can assist in answering candidates' queries and in routing incoming calls.

The senior organiser should inform the candidates, via the College, of the address of the examination centre, with clear travelling instructions and details of appropriate local accommodation. Our experience suggests that close to the examination all the preparatory work can be done in six working days by the senior organiser and the organiser. This allows for selection and contact of patients, preparation of case summaries and making administrative arrangements. Three days of secretarial time are required for the typing of summaries, time-tables etc.

To ensure adequate office space, six interview rooms, two waiting rooms, a reception area and a co-ordinating room (the 'nerve centre' of the operation) are required. Few hospitals will have purpose-built accommodation and therefore alternative rooms may have to be provided for the usual occupants of the examination centre. It may also be necessary to alter the take-in rota and out-patient clinics in the hospital. Each interview room requires furniture, as suggested by the College, including desks, chairs and ash-trays.

Selection of suitable patients is one of the most important tasks for the organisers. The College suggests that inpatients, day-patients or out-patients may be used. The patients should be able to demonstrate or to describe abnormal mental states. Dementia and mental handicap patients are excluded.

Final preparations, if made as close as possible to the examination, help to ensure reasonably smooth running. The day before the examination, case notes and summaries should be collected on all patients. An organiser timetable will lessen the possibility of confusion during the examination. To simplify matters we found it useful to prepare folders of summaries for each table of examiners for the four half days of the examination. This allows for flexibility for the often necessary changes in the planned timetable. Office space should be rearranged and signposting should be erected on the day before the examination.

\section{The examination day}

The day begins at 8.00 a.m. with the organisers ensuring that their arrangements and requests are being adhered to. If the preparation and planning have been good there follows a largely monotonous day with occasional episodes of panic among the organisers, chiefly due to the nonarrival of patients. We found that out-patients prove diffcult to arrange and overall were less reliable than in-patients or day-patients. An additional problem was the withdrawal of consent by patients on the day of the examination. In order to provide 32 cases we had identified 44 patients. In the event, because of non-attendance, clinical deterioration, alcohol dependent patients going drinking or withdrawal of consent, this was barely enough. The reserves must be easily accessible from the examination centre at short notice. For this reason, and because out-patients tend to become understandably disgruntled if not used in the examination, we recommend using in-patients as reserves. Perhaps because we did anticipate such a high level of drop-out among patients we found it necessary to use patients from other hospitals and to arrange for their transport. Taxis perform this service more quickly and more cheaply than the ambulance service can. In allocating patients' arrival times at the examination centre, compromise must be reached between avoiding boredom and ensuring punctuality. One of our patients felt that she had to wait for too long and left before being interviewed.

It is important to liaise with the medical staff looking after each patient. We found that at times it was necessary to update summaries on the day because of changes in treatment or in mental state.

The senior organiser is responsible for ensuring that the patients are paid. Patients, including reserves, are paid $£ 6.00$ each, plus travelling expenses, for their services. This is a particularly awkward sum requiring a mixture of notes and coinage to be held by the senior organiser. Reactions to receiving money varied. Some patients asked for it to be donated to charity and one lady commented that it was wonderful for her to be paid for someone to listen to her!

Apart from directing candidates, patients and examiners, most of the time is spent soothing frayed nerves. The candidates are helped by instructions being given simply and clearly and they appreciate advance warnings of timings.

\section{After the examination}

Following the examination there remains a considerable amount of paper containing personal information. This should be filed, shredded or incinerated as appropriate. The examiners' marking papers, together with expense claims, must be forwarded to 17 Belgrave Square. Offices should be returned to normal function and signposts removed. We believe that it is useful to audit the organisation, especially if the same venue is to be used again.

\section{Comments}

Organising any examination is time-consuming and offers numerous opportunities for disaster. This is particularly so in respect of a clinical examination. From our experience in organising MRCPsych Part I, on the first occasion it has been held, we would suggest that the risk of the untoward happening can be substantially reduced by careful planning, especially ensuring a large margin of error when choosing the number of patients.

\section{ACKNOWLEDGEMENTS}

We would like to thank all of those who helped in organising the examination, in particular Dr C. E. Adams (senior organiser). 
Rererences

'Royal College of Psychiatrists (1985) Working Party for Review of the MRCPsych. Approved by Council 17 October 1985.

2Thomas, D. J. B. (1987) How to arrange the clinical MRCP examination. British Journal of Hospital Medicine, September 1987.
${ }^{3}$ Cohen, H. N. (1987) Organise a clinical examination. British Medical Journal, 295, 714-715.

${ }^{4}$ ARMSTRONG, D. \& LOOSMORE, S. (1988) How to run the MRCPsych II examination. Bulletin of the Royal College of Psychiatrists, $12,229-230$.

\section{How to run the MRCPsych Part II Examination}

\section{Organising the clinical examination without affecting your mental health}

David Armstrong, Senior Registrar, Regional Secure Unit, Wakefield, Yorkshire and Simon Loosmore, Senior Registrar, Regional Addiction Unit, Birmingham

"the main thing about organising the exam is keeping the examiners happy" (Anonymous Professor and Examiner, 1987. personal communication)

The clinical examination is an artificial but unbettered assessment of the candidate's ability to assess a patient humanely, produce a formulation and treatment plan and speak knowledgeably on random aspects of psychiatry. It is the most important single part of the Part II examination and it must be passed. The emphasis is on general psychiatry. The new MRCPsych Part I also has a clinical component and the same administrative principles apply.

The aim is that the whole process passes off smoothly, with minimal stress to candidates, examiners, patients and staff. This helps the assessment of all concerned, including the examiners, if the College representative has come to check up on things.

The practical part of the examination has two components which take place on the same day:

(a) a clinical interview with a patient, lasting an hour, followed by a presentation to a pair of examiners, lasting 30 minutes, during which the patient is brought in

(b) a viva lasting 15 minutes with a different pair of examiners.

In Birmingham the examination runs over two days. About 30 candidates are timetabled in total although not all turn up; there is a drop out rate of about $10 \%$.

\section{Preparation}

The setting

The examination centre should be accessible and quiet. An out-patient department with normal activities suspended is ideal. A large number of conveniently situated rooms is needed; four rooms equipped for interview and physical examination, including working ophthalmoscope, sphygmomanometer and writing paper; three rooms for the examiners and candidates to meet, capable of taking at least four people, five if the College representative is there; three waiting rooms, one for the candidates, one for patients awaiting their interview and one for patients while they wait to be called in to meet the examiners and candidate together. Especially important is a co-ordination centre where the organiser can keep an eye on things and where notes, summaries, timetables and confidential papers can be safely stored. The rooms are made ready on the day before the examination although the porters should be given two weeks' warning in writing. The task requires two men for two hours.

\section{The staff}

The senior organiser should select an organiser to do his work for him. Senior registrars keen to obtain consultant posts in the region protest least when approached. He should have a list of hotels catering for a variety of tastes and pockets for those examiners staying overnight. He should not otherwise intrude. Two stewards, a cheerful receptionist and two nurses will also be needed, one to act as a chaperon.

\section{The patients}

In the fortnight preceding the examination junior doctors should be exhorted to select patients suitable for interviewing. A summary is required for each patient who appears in the examination. The examiners have ample time to study the clinical notes so it is not necessary to give a blow-byblow account of the patient's life unless the notes are of poor quality. There should be an outline of presenting problems, psychopathology and salient social and demographic details. For certain patients physical and neuropsychiatric findings should be included. Details of current treatment, in its broad sense, are important, diagnosis less so. In our experience the shortest summaries are prepared by postmembership registrars and GP vocational trainees, the longest by career psychiatrists at SHO grade. The best length is about one side of A4. There should be two copies for the examiners, one for the College assessor and one to allow for mishaps and unexpected demands. The examiners seem to be so pleased to have any summaries at all that they make no adverse comment. At present official guidelines on the form of the summary are scanty. 